\title{
Application of a Ridden Horse Pain Ethogram and Its Relationship with Gait in a Convenience Sample of 60 Riding Horses
}

\author{
Sue Dyson ${ }^{1, *(\mathbb{C}}$ and Danica Pollard ${ }^{2} \mathbb{C}$ \\ 1 Independent Consultant, The Cottage, Church Road, Market Weston, Diss IP22 2NX, UK \\ 2 Epidemiology and Disease Surveillance Department, Centre for Preventive Medicine, Animal Health Trust, \\ Newmarket, Suffolk CB8 7UU, UK; drdee.pollard@gmail.com \\ * Correspondence: sue.dyson@aol.com; Tel.: +44-(0)786-0826-028
}

Received: 16 April 2020; Accepted: 15 June 2020; Published: 17 June 2020

check for updates

Simple Summary: Horse owners are poor at recognising lameness which may compromise equine welfare. A Ridden Horse Pain Ethogram, comprising 24 behaviours with specific definitions, was developed to facilitate identification of musculoskeletal pain. Previous studies demonstrated that the presence of $\geq 8 / 24$ behaviours is likely to reflect musculoskeletal pain. The aim of this study was to further test the Ridden Horse Pain Ethogram by applying it to a convenience sample $(n=60)$ of sports horses and riding school horses in regular work and assumed by their owners to be working comfortably. All horses performed a purpose-designed dressage-type test of 8.5 min duration in walk, trot and canter, with their normal rider. The presence of increased back muscle tension or pain, poor saddle fit, gait abnormalities and rider skill were assessed by independent experts. The Ridden Horse Pain Ethogram was applied retrospectively, by a trained analyst, to video recordings which had been acquired in a standardised fashion. There was a significant association between the Ridden Horse Pain Ethogram score and lameness. Lame horses had higher scores than non-lame horses. Education of riders about behaviours which may reflect pain in ridden horses could allow the earlier identification of lame horses, whose welfare may be improved by accurate diagnosis and treatment.

Abstract: A Ridden Horse Pain Ethogram (RHpE) comprising 24 behaviours has been developed to facilitate the identification of musculoskeletal pain. The aim was to further test the RHpE by its application to a convenience sample $(n=60)$ of sports horses and riding school horses in regular work and assumed by their owners to be working comfortably. All horses performed a purpose-designed dressage-type test of $8.5 \mathrm{~min}$ duration in walk, trot and canter, with their normal rider. The RHpE was applied retrospectively to video recordings acquired in a standardised fashion. Seventy-three percent of horses were lame ( $\leq$ grade $2 / 8$ ) on one or more limbs; $47 \%$ had gait abnormalities in canter. Ridden Horse Pain Ethogram scores ranged from 3 to 16/24 (median 9); rider skill score ranged from 2.5 to $8 / 10$ (median 4.75). The effect of horse age, breed, sex, work-discipline, epaxial muscle hypertonicity or pain, an ill-fitting saddle, rider skill score, the presence of lameness or gait abnormalities in canter on the RHpE score was assessed using Poisson regression. Two variables were retained in the final multivariable analysis, rider skill score as a continuous variable $(p<0.001)$, and lameness $(p=0.008)$. A RHpE score $\geq 8$ was a good indicator of the presence of musculoskeletal pain.

Keywords: lameness; musculoskeletal pain; canter; behaviour; dressage; riding school; saddle-fit; rider skill; thoracolumbar pain 


\section{Introduction}

In 2012 it was estimated that there were at least 840,000 horses in Great Britain [1]. There is limited information available about the frequency of occurrence of lameness and other sources of musculoskeletal pain in sports horses and riding school horses. In the United Kingdom's Blue Cross National Equine Health survey for 2018, lameness accounted for $23 \%$ of all disease syndromes reported for 13,873 horses [2]. However, there is evidence that owners and trainers are poor at lameness recognition; in a United Kingdom survey of 506 sports horses in full work and presumed to be non-lame, $47 \%$ were lame or had other pain-related gait abnormalities [3]. In a Swedish study of sports horses in full work and functioning normally, 53\% of 201 horses showed measurable asymmetry of gait when trotted in hand [4].

In order to facilitate the recognition of musculoskeletal pain in ridden horses, a Ridden Horse Pain Ethogram (RHpE) was developed, comprising 24 behaviours, the majority of which were at least 10 times more likely to be seen in a lame horse compared with a non-lame horse [5]. Reduction in RHpE behaviour scores, after diagnostic anaesthesia had abolished lameness, verified a causal relationship between the behaviours and pain [6,7]. The display of eight or more behaviours of the RHpE is likely to reflect the presence of musculoskeletal pain [5-8]. Previous work has focused on comparisons between non-lame horses and horses undergoing veterinary investigation of lameness or poor performance.

Veterinarians, after appropriate training, were able to predict the presence of musculoskeletal pain by application of the RHpE [8]. Other factors which may potentially influence the results of applying the RHpE include an ill-fitting saddle [9], rider size (influenced by height, weight and saddle fit for the rider) [10-12] and rider skill [13].

The aim of the current study was to further test the RHpE by its application to a convenience sample of sports horses and riding school horses in regular work and assumed by their owners to be working comfortably. It was hypothesised that there would be a positive association between the RHpE behaviour score and the presence of lameness and/or gait abnormalities in canter.

\section{Materials and Methods}

\subsection{Data Acquisition}

A convenience sample of 64 horse-rider combinations was recruited, comprising volunteers from a further education college (Riding School) and privately owned horses. Horses had to be used to working 'on the bit' (with the front of the head in a vertical position), in regular work, and considered by their owners to be non-lame and capable of working for $30 \mathrm{~min}$ in trot and canter. Each horse rider combination was unique; no rider rode more than one horse. Age (years), breed (Warmblood, Thoroughbred, Warmblood $\times$ Thoroughbred, Cob, Irish Sports Horse or other), sex (mare or gelding) and work discipline (Eventing, Show Jumping, Dressage, General Purpose (including unaffiliated competition), Riding School) were recorded. With the horse standing squarely, before exercise, the thoracolumbosacral region of each horse was palpated by an experienced physiotherapist, using a standardised method. The presence of thoracolumbosacral epaxial muscle hypertonicity (increased muscle tension) and/or pain, subjectively considered to be likely to influence ridden performance, was graded using a binary outcome, yes or no. The saddle of each horse was assessed off the horse and after the rider had tacked up the horse, by a Society of Master Saddlers qualified saddle fitter. The tree stability and soundness, panel and tree symmetry, flocking condition, girth strap alignment and the static fit of the saddle plus pads to the horse were assessed. The fitter was asked to determine whether the tack was likely to induce pain which may compromise performance, graded in binary fashion, yes or no. The riders were advised to use their normal tack; a whip and/or spurs were optional.

All owners gave their informed consent for inclusion prior to participation in the study. The study was conducted in accordance with the Declaration of Helsinki, and the protocol was approved by the Ethics Committees of the Animal Health Trust (AHT 50 2017) and Writtle University (2019). The results for 20 horses have been previously documented [8]. 
Each horse was ridden by its usual rider. There was a free-exercise warm-up of up to $15 \mathrm{~min}$ in an indoor or outdoor arena. Horses which exhibited $\geq$ grade 3/8 [14] forelimb or hindlimb lameness, as determined by a Diplomate of the European College of Veterinary Sports Medicine and Rehabilitation $(\mathrm{SD})$, during this warm-up were excluded $(n=4)$. Each horse and rider combination then performed a purpose-designed dressage-type test of approximately 8.5 min duration, at walk, trot and canter (Supplementary Materials Table S1 [8]) in a marked $20 \times 40 \mathrm{~m}$ area (Figure 1), within an indoor arena, at one of three locations. The arena surfaces were sand and rubber. All trot work was performed in rising trot. All $20 \mathrm{~m}$ diameter circles were performed at C, close to the video camera; $10 \mathrm{~m}$ diameter circles were performed at B and E, respectively. The test, which was of British Dressage Preliminary standard, with the addition of $10 \mathrm{~m}$ diameter circles in trot, was called, although the riders had been provided with it in advance.

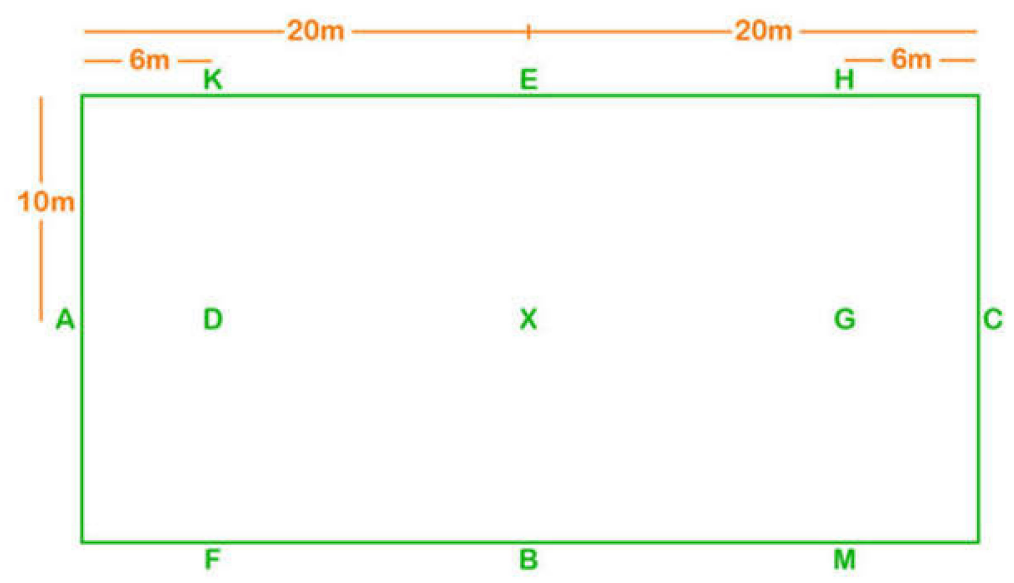

Figure 1. Layout of the dressage arena in which 60 horse rider combinations performed a custom-written dressage test (Table S1). The video recorder stood between $\mathrm{M}$ and C, and H and C, for movements 1-9 and 11-26, respectively.

Video recordings of all tests were acquired from two locations, behind the long sides of the arena, between $M$ and $C$, and $H$ and $C$ for movements 1-9 and 11-26 (Table S1), respectively. Video recordings were acquired with a high-definition video camera (Panasonic HC-X900, Panasonic Corporation, Hamburg, Germany). Before each test, the size of the iris of each eye and whether or not the sclera could be seen at rest were assessed. Exposure of the sclera at rest and the presence of a bit which was too wide were recorded and referred to when applying the RHpE [5,8].

Throughout the test the gait was assessed subjectively by an experienced lameness diagnostician, used to evaluating ridden horses. The presence of forelimb lameness, hindlimb lameness or lack of hindlimb impulsion and engagement, or an abnormal canter (a stiff and stilted canter, close spatial and/or temporal placement of the hindlimbs, a canter which lacked a suspension phase [15,16], or exaggerated lifting of the forehand during canter, associated with abnormally wide spatial separation of the hindlimbs [17]) was recorded. Lameness was graded on a 0-8 scale [14].

The RHpE (Table 1) [5] was applied retrospectively to the video recordings by a trained assessor, without knowledge of the live gait assessment results. The video recordings were also assessed independently by a British Horse Society Instructor, who graded the skill of the rider on the Fédération Equestre Internationale 1-10 scale (Supplementary Materials Table S2) [18] based on application of the aids, balance, position and core stability. This assessor was blinded to all other results, the experience of the riders and the work discipline of the horses.

All riders were provided with both verbal and written feedback about the results of palpation of the thoracolumbosacral region, saddle-fit and gait abnormalities after completion of their tests. 
Table 1. The Ridden Horse Pain Ethogram, adapted from Dyson et al. 2018 [5]. Assessments were made in walk, trot and canter and on the left and right reins. A total behaviour score of $\geq 8$ (out of 24 ) is likely to indicate the presence of musculoskeletal pain (Dyson et al. $2018[5,6]$ ). $\mathrm{s}=$ seconds.

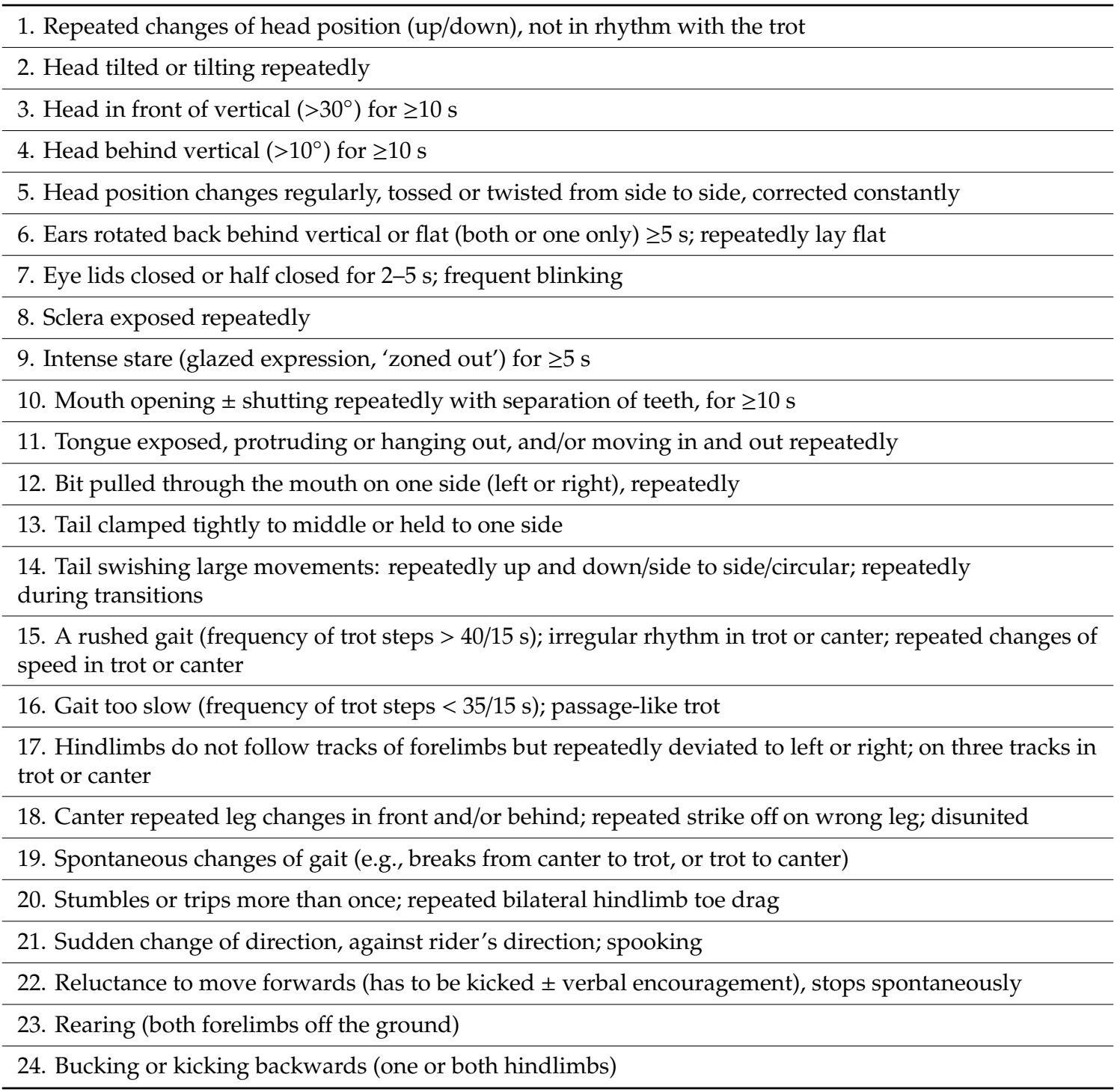

\subsection{Data Analysis}

Data were collated into a Microsoft Excel (Office 365) spreadsheet (Microsoft Corporation, Redmond, Washington, USA) and imported into statistical software Stata (IC v.13.0, StataCorp LP, College Station, TX, USA) for coding and analyses.

\subsection{Descriptive Statistics}

Normality of distribution for continuous variables was visually assessed with histograms and overlaid normal and kernel density plots. Continuous and ordinal variables were described as medians with corresponding ranges and interquartile ranges (IQR), and categorical variables were described as proportions with $95 \%$ confidence intervals (CI).

\subsection{Initial Associations}

The prevalence of each of the $24 \mathrm{RHpE}$ behaviours was compared between lame and non-lame horses with a Fisher's exact test. Differences in RHpE scores across categorical variables were initially 
assessed using the Mann-Whitney $U$ test for variables with two categories, and the Kruskal-Wallis test for variables with more than two categories. The Spearman rank correlation coefficient was used to assess correlations between $\mathrm{RHpE}$ score and horse age and rider skill score. Significance was set at $p<0.05$ and $p$-values were adjusted for multiple comparisons using the Benjamini-Hochberg false discovery rate methods, with a false discovery rate of 0.05 [19]. Both unadjusted and adjusted $p$-values are presented.

\subsection{Poisson Regression}

Univariable Poisson regression, with robust standard errors, was used to calculate incident rate ratios (IRR) and corresponding 95\% CIs in order to identify factors associated with higher RHpE scores [20]. The use of robust standard errors is recommended in Poisson regression in order to control for mild violations of the underlying assumptions, most notably the assumption that the mean and variance of the outcome variable distribution are equal [20]. Age was additionally recoded into quartile categories in order to test for evidence against linearity. Variables where Wald $p<0.25$ were taken forward to multivariable Poisson regression modelling. Manual, forward selection was used to create the final multivariable Poisson regression model, with robust standard errors, and variables were added to the model in a stepwise manner from most to least significant based on their Wald $p$-values. Variables were retained in the final model where Wald $p<0.05$ and if they significantly improved model fit in a model without robust standard errors (likelihood ratio statistic $p<0.05$ ). All variables not retained in the final model were individually forced back into the model in order to not omit any interactions or confounders. The goodness-of-fit chi-squared test was used to assess the fit of the model to the data.

\section{Results}

\subsection{Descriptive Statistics}

The median age of the horses was 11 years (IQR 9-14; range 5-24 years). Breeds were comprised of 16 Warmbloods $(26.7 \%$, CI 15.5, 37.9), 13 Irish Sports Horses (21.7\%, CI 11.2, 32.1), nine Thoroughbreds (15.0\%, CI 6.0, 24.0\%), eight Cobs (13.3\%, CI 4.7, 21.9\%), six Warmblood $\times$ Thoroughbreds (10.0\%, CI 2.4, $17.6 \%)$ and eight other breeds (13.3\%, CI 4.7, 21.9\%) including three Connemara ponies, two Welsh ponies, one Andalusian, one Irish Draught and one Shire. The majority of the horses were geldings $(n=36 ; 60 \%, \mathrm{CI} 47.6,72.4 \%)$ rather than mares $(n=24 ; 40 \%, \mathrm{CI} 27.6,52.4 \%)$. The most common work discipline was General Purpose $(n=26 ; 43.3 \%$, CI 30.8, 55.9\%), followed by Dressage $(n=12 ; 20.0 \%$, CI 9.9, 30.1\%) and Riding School ( $n=11 ; 18.3 \%$, CI 8.5, 28.1\%), with the least number of horses in the Eventing $(n=8)$ and Show Jumping $(n=3)$ disciplines. Lameness was recognised in 73.3\% (CI 62.1, $84.5 ; n=44)$ of the horses, while $46.7 \%$ (CI 34.0, 59.3\%; $n=28)$ had abnormalities in canter. Twenty-two $(36.7 \%$, CI $24.5,48.9 \%)$ horses were both lame and had an abnormal canter. Increased tension or pain in the thoracolumbosacral epaxial muscles was identified in 58.3\% (CI 45.9, 70.8\%; $n=35$ ) of the horses, while $46.7 \%$ (CI 34.0, 59.3\%; $n=28$ ) were found to have saddle fit which could negatively affect performance. The median rider skill score was 4.75 (IQR 4-5.5; range 2.5-8). The median RHpE score out of 24 was 9.0 (IQR 7-11; range 3-16).

\subsection{Initial Associations}

When considering the prevalence of RHpE behaviours in lame and non-lame horses, in the unadjusted analysis lame horses were more likely to flatten or rotate their ears backwards $(p=0.03)$, exhibit an intense stare $(p=0.02)$ and stumble or trip repeatedly ( $p=0.04)$ compared with non-lame horses (Table 2). However, the significance of these findings was not retained following adjusting for multiple comparisons. Results of the unadjusted Mann-Whitney $U$ and Kruskal-Wallis tests indicated that higher RHpE scores were associated with lameness $(p=0.02)$ only. However, potential associations of interest $(p<0.10)$ additionally included sex $(p=0.07)$ and work discipline $(p=0.07)$ (Table S3). 
Mares had higher RHpE scores compared with geldings, and Riding School horses had the highest median RHpE scores from all the work disciplines. Following adjustment for multiple comparisons, only lameness $(p=0.18)$ and work discipline $(p=0.21)$ retained an adequate level of significance in relation to the $p<0.25$ cut-off used for screening variables for inclusion in multivariable analyses. A correlation between horse age and RHpE score was not identified (Spearman's rho $=0.04, p=0.77$ ). Rider skill score had a negative correlation with RHpE score (Spearman's rho $=-0.45, p=0.0003$, adjusted $p=0.0006$ ).

Table 2. The prevalence, difference in prevalence and Fisher's exact $p$-value of 24 Ridden Horse Pain Ethogram behaviours compared between lame and non-lame ridden horses $(n=60)$.

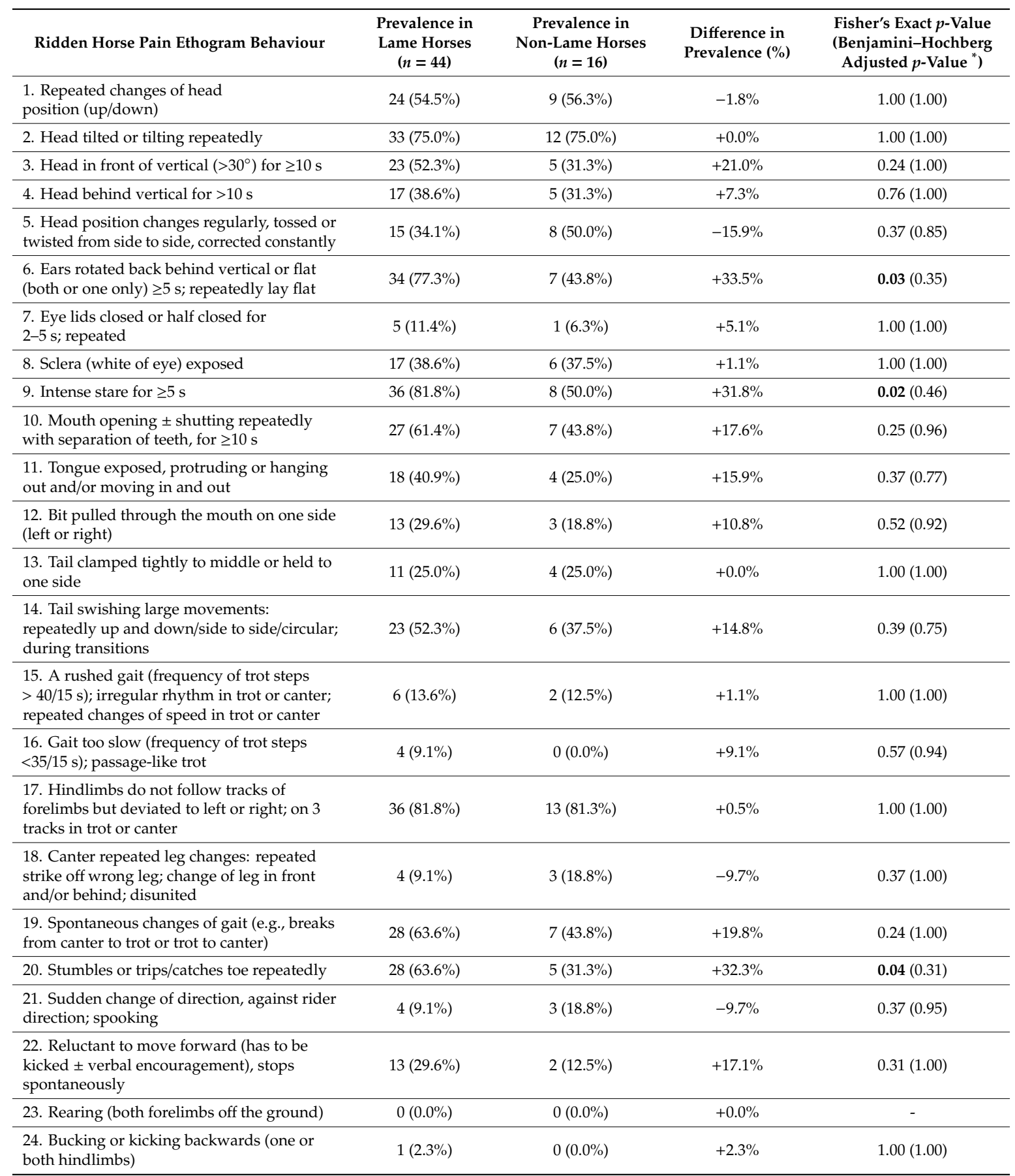

${ }^{*}$ False discovery rate $p$-value of 0.05 to adjust for multiple comparisons; bold values indicate significance at $p<0.05$. 


\subsection{Poisson Regression}

Univariable Poisson regression analysis identified six variables to take through to multivariable modelling (Table 3). These included rider skill score $(p<0.001)$, work discipline $(p<0.001)$, lameness $(p=0.03)$, both lameness and abnormal canter $(p=0.08)$, sex $(p=0.09)$, abnormal canter $(p=0.12)$ and age $(p=0.17)$. The results of the univariable Poisson regression model complement the findings of the initial pairwise comparisons, with lameness status and work discipline identified as variables with the strongest relationship with RHpE score. Similarly, correlation analysis had identified a strong negative linear relationship between $\mathrm{RHpE}$ score and rider skill score, which was replicated in the regression analysis, helping describe how rider skill score was numerically related to RHpE score.

Table 3. Univariable Poisson regression, including robust standard errors, of signalment, work discipline and lameness-related variables associated with Ridden Horse Pain Ethogram scores in a convenience sample of 60 horses. $\mathrm{CI}=$ confidence intervals.

\begin{tabular}{|c|c|c|c|c|c|}
\hline Variable & Coefficient & $\begin{array}{l}\text { Robust } \\
\text { Standard Error }\end{array}$ & $\begin{array}{l}\text { Incident Rate } \\
\text { Ratio (IRR) }\end{array}$ & IRR 95\% CI & Wald $p$-Value \\
\hline Age (continuous) & 0.02 & 0.01 & 1.02 & $0.99,1.04$ & 0.165 \\
\hline 5-9 years & Reference & & Reference & & \\
\hline 10-11 years & -0.02 & 0.10 & 0.98 & $0.81,1.18$ & 0.83 \\
\hline $12-14$ years & -0.16 & 0.12 & 0.86 & $0.68,1.07$ & 0.18 \\
\hline Warmblood & Reference & & Reference & & \\
\hline Irish Sports Horse & -0.06 & 0.21 & 0.94 & $0.63,1.42$ & 0.18 \\
\hline Thoroughbred & 0.17 & 0.14 & 1.19 & $0.90,1.57$ & 0.22 \\
\hline $\mathrm{Cob}$ & 0.19 & 0.11 & 1.21 & $0.98,1.50$ & 0.08 \\
\hline Warmblood $\times$ Thoroughbred & 0.17 & 0.13 & 1.18 & $0.93,1.51$ & 0.79 \\
\hline Gelding & Reference & & Reference & & \\
\hline Work discipline & & & & & $<0.001$ \\
\hline General purpose & Reference & & Reference & & \\
\hline Dressage & 0.01 & 0.12 & 1.01 & $0.79,1.29$ & 0.94 \\
\hline Riding School & 0.24 & 0.08 & 1.27 & $1.08,1.50$ & 0.004 \\
\hline Eventing & 0.08 & 0.12 & 1.09 & $0.86,1.38$ & 0.48 \\
\hline Show Jumping & -0.10 & 0.10 & 0.90 & $0.74,1.10$ & 0.32 \\
\hline Lame & & & & & 0.027 \\
\hline Yes & 0.24 & 0.11 & 1.27 & $1.03,1.58$ & \\
\hline No & Reference & & Reference & & \\
\hline Abnormal canter & & & & & 0.119 \\
\hline Yes & -0.07 & 0.08 & 0.93 & $0.80,1.09$ & \\
\hline No & Reference & & Reference & & \\
\hline $\begin{array}{l}\text { Saddle fit likely to negatively } \\
\text { affect performance }\end{array}$ & & & & & 0.530 \\
\hline Yes & -0.05 & 0.08 & 0.95 & $0.80,1.12$ & \\
\hline No & Reference & & Reference & & \\
\hline Rider skill score (continuous) & -0.13 & 0.03 & 0.88 & $0.83,0.94$ & $<0.001$ \\
\hline
\end{tabular}

Bold values indicate significance at $p<0.25$.

The final multivariable Poisson regression model identified associations between RHpE score and both rider skill score and lameness (Table 4). The change in the incident rate of RHpE scores decreased by 0.88 for every unit increase in rider skill score $(p<0.001)$. The incident rate of RHpE scores for lame 
horses was 1.26 times higher than for non-lame horses $(p=0.008)$. The predicted RHpE score from the model, given rider skill score and lameness status, is presented in Figure 2. The goodness-of-fit chi-squared test indicated the Poisson model was an adequate fit for the data (goodness-of-fit $\chi^{2}=41.8$, $p=0.93$ ). Although work discipline was not retained in the final model, this is likely because there is a relationship between rider skill score and work discipline, with riders of Riding School horses having the lowest median rider skill score from all the work disciplines (Kruskal-Wallis $p=0.001$ ) (Figure 3). A difference in lameness across the work disciplines was not identified $(p=0.43)$.

The results of the multivariable analysis clearly show a strong positive relationship between the presence of lameness and the RHpE score. All non-lame horses that had a normal canter had a RHpE score $<8$ (median 5, range 3-6), with the exception of one Riding School horse and one General Purpose horse. Moreover, 10 of 11 Riding School horses had gait abnormalities consistent with musculoskeletal pain and Riding School horses had the highest median RHpE score from all work disciplines. A RHpE score $\geq 8$ is likely to reflect the presence of musculoskeletal pain.

Table 4. The final multivariable Poisson regression, including robust standard errors, of signalment, work discipline and lameness-related variables associated with Ridden Horse Pain Ethogram scores in a convenience sample of 60 horses. $\mathrm{CI}=$ confidence intervals.

\begin{tabular}{cccccc}
\hline Variable & Coefficient & $\begin{array}{c}\text { Robust } \\
\text { Standard Error }\end{array}$ & $\begin{array}{c}\text { Incident Rate } \\
\text { Ratio (IRR) }\end{array}$ & IRR 95\% CI & Wald $\boldsymbol{p}$-Value \\
\hline $\begin{array}{c}\text { Rider skill score } \\
\text { (continuous) } \\
\text { Lame } \\
\text { Yes } \\
\text { No }\end{array}$ & -0.13 & 0.03 & 0.88 & $0.83,0.94$ & $<\mathbf{0 . 0 0 1}$ \\
\hline \begin{tabular}{c} 
Reference \\
\hline
\end{tabular} & 0.09 & $\begin{array}{c}1.26 \\
\text { Reference }\end{array}$ & $1.06,1.50$ & $\mathbf{0 . 0 0 8}$ \\
\hline
\end{tabular}

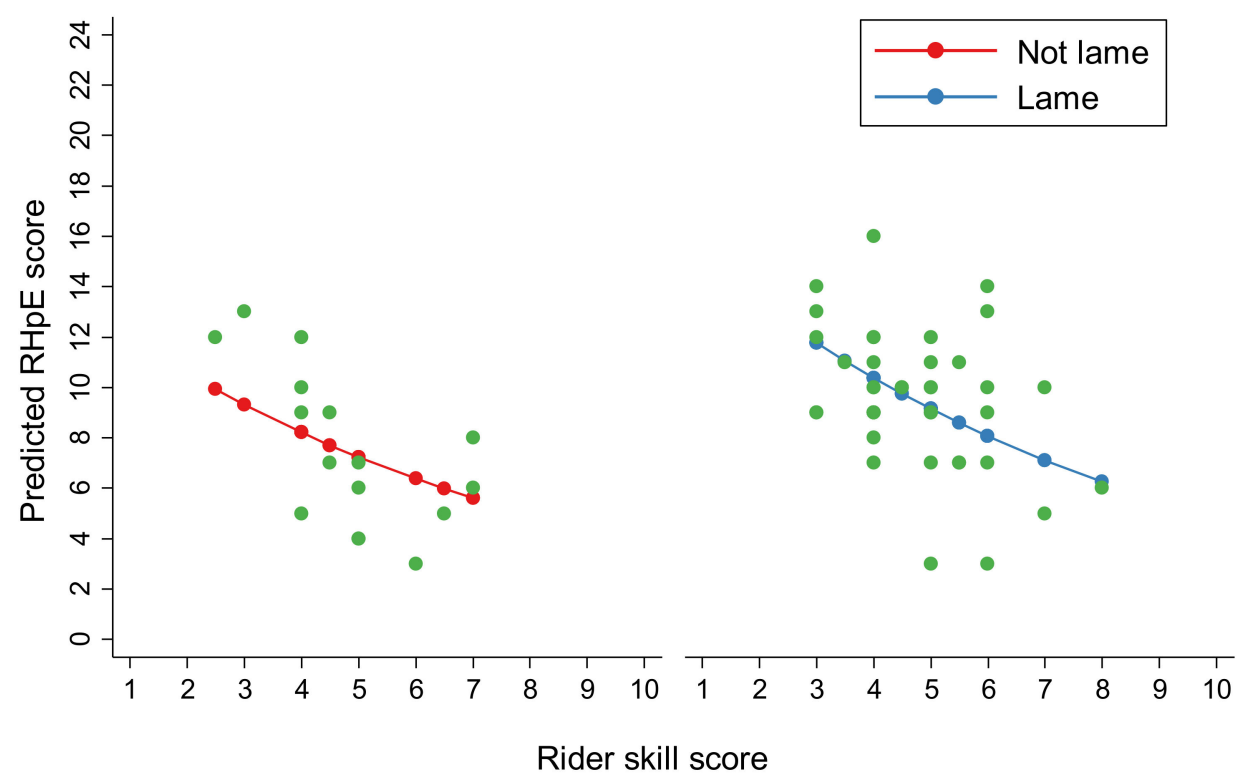

Figure 2. Prediction of linear Ridden Horse Pain Ethogram (RHpE) scores based on rider skill score $(0-10)$ and lameness status (red = non-lame; blue = lame), as estimated by a multivariable Poisson regression model with robust standard errors. Individual points (green) represent the original data used to make these linear predictions. 


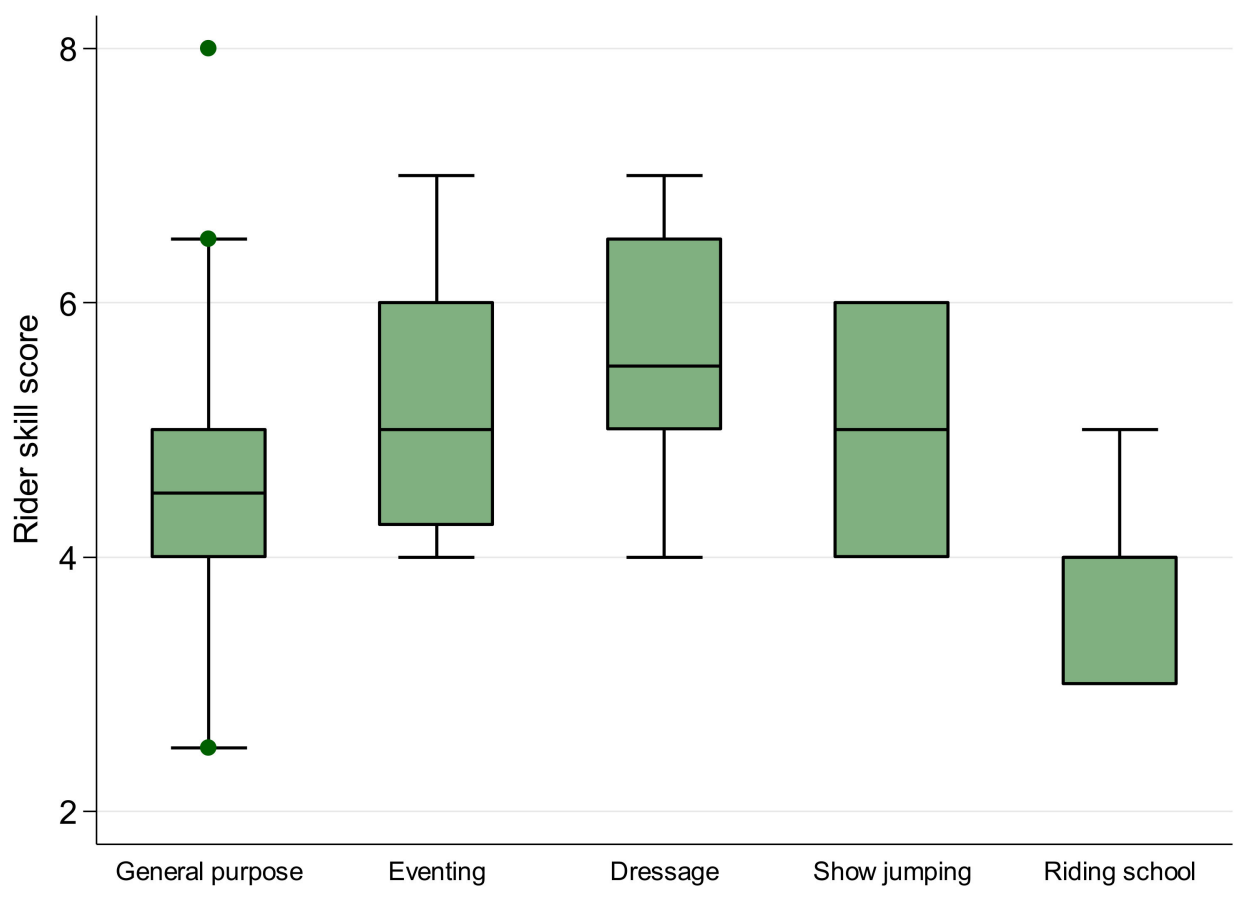

Figure 3. Median rider skill scores (0-10) of 60 riders across five equestrian work disciplines. Boxes represent medians and interquartile ranges, whiskers represent the range and individual points outliers.

\section{Discussion}

In accordance with our hypothesis there was a positive association between RHpE scores and the presence of lameness and, given the results of previous studies [6-8], this is likely to be a causal relationship. However, contrary to our hypothesis, gait abnormalities in canter, either alone or in combination with lameness, although carried forward to the multivariable analysis, were not significant in the final model. In addition, rider skill score was negatively associated with the RHpE score. However, this may not be a causal relationship. Although work discipline was not retained in the final model, this is probably because riders of the Riding School horses, which had the highest median RHpE score, had the lowest median rider skill score from all the work disciplines.

There are several studies which demonstrate that unskilled novice riders have a less stable position and lack of phase synchrony with the horse compared with riders of superior skill and experience [21-24]. These features have the potential to alter the horse's head and neck position [25], lameness [26], and quality of gaits [27]. However, we have previously observed during clinical investigation of lame horses that, when ridden by a skilled professional, the rider may appear to ride relatively poorly. However, when gait abnormalities are abolished by local anaesthesia, the rider then appears to be both more in harmony with the horse and considerably more proficient. Moreover, 40 of the horses in the current study were part of a related study in which all horses were ridden by the normal rider and a professional rider [28]. The professional rider's skill score ranged from 3.5 to 7/10 (median 6), being strongly influenced by the presence (low rider skill score) or absence (high rider skill score) of lameness [28]. In a study involving eight riders, four beginners and four more experienced riders, and eight riding school horses there was no effect of rider skill on a limited number of horse behaviours [13]. As might be expected, in the current study rider skill level was higher for horses used for affiliated level competition compared with General Purpose and Riding School horses, but overall the median score was low (4.75/10), corresponding to less than sufficient as defined by the Fédération Equestre Internationale [18]. It remains possible that an unskilled rider riding a pain-free horse may alter its behaviour. 
There was a high frequency of low-grade ( $\leq$ grade $2 / 8$ [14]) lameness $(73 \%)$ and other gait abnormalities (47\%) in the current study, reflecting owners' inability to recognise musculoskeletal pain, as previously documented [3,4,29]. It should be borne in mind that in horses with lameness in more than one limb, as frequently observed in the current study, the grading of lameness may be neither accurate nor reflect the level of discomfort [14]. Education of riders and trainers about the value of the $\mathrm{RHpE}$ for detecting the likely presence of musculoskeletal pain may prompt them to seek professional advice. Lameness was not necessarily a continuous feature, but was often accentuated in $10 \mathrm{~m}$ diameter circles in trot, highlighting the value of this exercise when investigating poor performance and at pre-purchase examinations. The test performed by the riders was purpose-designed to include 10 $\mathrm{m}$ diameter circles because it has previously been observed that this movement can influence both lameness and behaviour [6]. This study also reinforces the importance of evaluating the quality of canter, which may be compromised especially in association with hindlimb lameness or sacroiliac joint region pain [17,30-32]. Although gait abnormalities in canter were not significant in the final model, it does not mean that such abnormalities are not of biological significance. It has previously been observed, in a minority of horses, that no behavioural or gait abnormalities were detectable in trot, whereas gait abnormalities in canter were seen in association with a high RHpE score [6].

Of the Riding School horses 9/11 (82\%) showed lameness and 6/11 (55\%) displayed gait abnormalities in canter; only one horse was graded as displaying no gait abnormalities, but this horse worked consistently with the front of the head in front of the vertical $>30^{\circ} \geq 10 \mathrm{~s}$ and had reduced range of motion of the thoracolumbosacral region, and had a RHpE score of 13. Overall, the median RHpE score for the Riding School horses was higher than for the other work disciplines. There are limited published data concerning riding school horses. In a Swedish study of 99 horses from eight riding schools, 15 exhibited 'moderate lameness' in hand or on the lunge, including eight with gait abnormalities in canter [33]. However, 'irregular movement' (presumably low-grade lameness) was observed in an additional 45 limbs and a further 17 horses were described as 'moving short' and nine 'moved flat on the ground'. Thus, potentially up to $87 \%$ of the horses had gait abnormalities reflecting musculoskeletal pain. In a cross-sectional study of 2566 Dutch riding horses from 150 horse farms, $19.3 \%$ were lame or had 'irregular locomotion' when assessed moving in hand by trained veterinary students [34]. Riding school horses had a higher risk of lameness than horses used for recreation or competition. The sample size of Riding School horses in the current study was small, but if it is representative of the United Kingdom Riding School population, the high incidence of lameness and RHpE scores $\geq 8$ is of cause for concern. Under the Riding Establishments Act (1964) horses have to undergo a statutory annual veterinary inspection to determine that they are 'in all aspects physically fit'. This examination does not require horses to be ridden. Education of riding school proprietors about the RHpE and the use of ridden exercise and application of the RHpE by veterinarians during their inspections may enhance riding school horse welfare.

The RHpE scores ranged from 3 to $16 / 24$, with a median of 9 . These scores were substantially higher than those documented at three $5^{*}$ three-day events during warm-up for the dressage phase, at which the scores of 172 horses ranged from 0 to 9 (median 4) [35,36]. In the latter studies, horses with a score $\geq 7 / 24$ performed significantly less well in the dressage and cross-country phases and had lower overall places, compared with horses that scored $<7$. In the current study, with the exception of one Riding School horse and one General Purpose horse, all non-lame horses that had a normal canter had a RHpE score $<8$ (range 3-6, median 5), consistent with previous reports [5-7]. This reinforces that a RHpE score $\geq 8$ is likely to reflect musculoskeletal pain. We have previously demonstrated through assessment of sensitivity and specificity that a threshold of 8 is appropriate for the differentiation of horses with and without musculoskeletal pain [7]. It was clear that riders, irrespective of their skill level and experience, had a lack of recognition of the behavioural signs which may reflect musculoskeletal pain. We believe that many riders learn to ride on riding school horses which exhibit these signs, so that there is a generalised acceptance that these behaviours are normal for horses. There is an urgent 
need for education of riders and trainers at all levels to recognise that demonstration of eight or more behaviours of the RHpE is highly likely to reflect musculoskeletal pain.

Overall, the incident rate of each of the RHpE scores for lame horses was 1.27 times the incident rate for the non-lame horses. Those features which had the strongest relationship with lameness were ears back for $\geq 5 \mathrm{~s}$, an intense stare for $\geq 5 \mathrm{~s}$, and repeated stumbling or bilateral hindlimb toe drag, similar to previous observations [7]. Although these associations were not retained following adjustment for multiple comparisons, this likely reflects the limitations of the sample size and the variation with which individual horses show pain-related behaviours. As previously documented $[5,6]$ and as illustrated in Table 2, different horses show different behaviour patterns and therefore reliance on a limited spectrum of behaviours is potentially misleading.

In the current study the presence of thoracolumbosacral epaxial muscle pain or increased muscle tension did not influence the RHpE score. Although palpation is a subjective assessment, there is evidence that it may be more reliable than more objective assessments [37]. There is a relationship between the presence of either lameness [38] or sacroiliac joint region pain [32] and epaxial muscle hypertonicity and pain. We have observed that when pain associated with lameness or sacroiliac joint region pain is abolished using local anaesthesia, there is a substantial reduction in the $\mathrm{RHpE}$ scores, despite the persistence of epaxial muscle hypertonicity or pain [6,7], which is consistent with the results of the current study.

There was a disturbingly high proportion ( $47 \%$ ) of ill-fitting saddles with the potential to adversely influence performance. However, in the current study, saddle fit did not influence the RHpE score. Nonetheless, a change from an ill-fitting saddle to a better fitting saddle may have a dramatic influence on ridden horse behaviour [39]. Twenty-one horses were assessed ridden by a single professional rider in both a well-fitting saddle and an ill-fitting saddle [40]. There was significantly less variability in gait with the better-fitting saddle compared with the ill-fitting saddle. It is therefore considered important to address saddle fit when assessing a horse with poor performance. If a high RHpE score persists after abolition of lameness using diagnostic anaesthesia this usually indicates the presence of an additional problem, such as an ill-fitting saddle, meriting further investigation $[7,41]$.

A small proportion ( $3 \%$ ) of horses that had a RHpE score of $\geq 8$ did not show overt lameness or gait abnormalities, as defined, in canter. There are other gait variants which are likely to reflect adaptations to musculoskeletal pain which are not covered by the conventional understanding of lameness, the definitions employed for this study, or behaviours within the ethogram. These include a short stepping forelimb gait; reduced range of motion of the thoracolumbosacral region; reduced flexion of the lumbosacral joint; 'on the forehand'; scooting forwards episodically; 'jumping' into transitions to trot from walk; transiently going above the bit in upward transitions; stepping short on the hindlimbs in downward transitions from canter to trot, or from trot to walk; 'croup high' in canter; and altered movement of the thoracolumbar region in canter resulting in rotation of the rider's pelvis $[15,16,30,32,42]$. It is therefore suggested that it is crucial to apply the RHpE to horses performing both trot and canter and also to observe behaviour and movement quality in transitions between gaits.

An inherent limitation of the study design is that the trained assessor who applied the RHpE could not be blinded to the lameness status of the horse, work quality or the skill of the rider. Assessment of epaxial muscle tension or pain, saddle fit, lameness and canter, and rider skill were all subjective, but were performed by independent experts, with no knowledge of the RHpE scores. Quantitative assessment of ridden horse gait [43] has many limitations, especially in a horse lame on more than one limb, and for lameness that varies between reins and different movements, and cannot be used to assess transitions between gaits or canter. The gait may alter between rising and sitting trot and vary depending on the diagonal on which the rider sits $[15,43]$, however, in the current study all trot work was performed in rising trot, because the majority of the riders rarely rode in sitting trot. Riders sat on the correct diagonal, when the outside forelimb and inside hindlimb were bearing weight. There are other potential confounders that were not identified or measured in the current study. For example, although bit fit was assessed, the mouth was not inspected, so the presence of oral lesions that could 
have contributed to discomfort cannot be excluded. Noseband type and fit were recorded, but not included in the analyses. Poisson regression generally requires a large sample size, so it is likely that our model did not have sufficient power to detect more subtle associations. However, the results of the Poisson regression reflected the results of the pairwise comparisons and allowed us to fully utilise the data and to assess the effect of multiple variables on RHpE scores in the same model. The study population was a convenience sample and may not be representative of the United Kingdom horse population as a whole.

There has been limited comparison between physiological markers of stress and ridden horse behaviour [44]. In a previous review of ridden horse behaviour, the difficulties of differentiation between behaviour reflecting pain, anxiety, fear and mental state were highlighted, together with the potential overlap between physiological signs of stress and the response to physical exertion [45]. The RHpE appears to provide a simple method of determining the likely presence of musculoskeletal pain, with the current study providing further evidence of the strong association between a $\mathrm{RHpE}$ score $\geq 8$ and the presence of lameness.

\section{Conclusions}

There was a negative association between rider skill score and the RHpE score, but this is not believed to be a causal relationship. There was a positive association between lameness and the RHpE score, and this provides further evidence that a score of $\geq 8 / 24$ reflects the presence of musculoskeletal pain. A relationship between $\mathrm{RHpE}$ score and work discipline was not found to be significant after adjustment for lameness and rider skill score, although Riding School horses had the highest median RHpE scores out of all the other work disciplines. This is likely because of a strong relationship between work discipline and rider skill score, with riders of riding school horses having lowest median rider skill scores. Behaviours exhibited by many riding school horses are likely to reflect chronic discomfort and should not be regarded as typical behaviour of pain-free horses. Education of owners, riders, trainers and all associated professionals is required about what constitutes abnormal horse behaviour, so that lame horses are recognised and undergo appropriate investigation and treatment, in order to both enhance equine welfare and improve performance.

Supplementary Materials: The following are available online at http://www.mdpi.com/2076-2615/10/6/1044/s1.

Author Contributions: Conceptualization, S.D.; Data curation, D.P.; Formal analysis, D.P.; Funding acquisition, S.D.; Investigation, S.D.; Methodology, S.D.; Project administration, S.D.; Software, D.P.; Writing一original draft, S.D. and D.P. All authors have read and agreed to the published version of the manuscript.

Acknowledgments: World Horse Welfare for providing funding and facilities. Alexander Cairns and Claire Martin for facilitating arrangements at a private livery yard. Daniel Cook, Robin Gill, Jane Hart and Claire Martin for facilitating arrangements at Writtle University. Anne Bondi, British Horse Society Instructor; Laura Quiney MRCVS; Liz Suddaby and Georgie Welge, Society of Master Saddlers Qualified Saddle Fitters; Jo Spear and Rhian Williams, Veterinary Physiotherapists. Victoria Mensley, Mollie Stephens and Sam White, who called the tests.

Conflicts of Interest: The authors declare no conflict of interest.

\section{References}

1. Boden, L.; Parkin, T.D.; Yates, J.; Mellor, D.; Kao, R.R. Summary of current knowledge of the size and spatial distribution of the horse population within Great Britain. BMC Vet. Res. 2012, 8, 43. [CrossRef] [PubMed]

2. Blue Cross. 2018. Available online: www.bluecross.org.uk/sites/default/files/NEHS (accessed on 31 March 2020).

3. Greve, L.; Dyson, S.J. The interrelationship of lameness, saddle slip and back shape in the general sports horse population. Equine Vet. J. 2014, 46, 687-694. [CrossRef]

4. Rhodin, M.; Roepstorff, L.; French, A.; Keegan, K.G.; Pfau, T.; Egenvall, A. Head and pelvic movement asymmetry during lungeing in horses showing symmetrical movement on the straight. Equine Vet. J. 2016, 48, 315-320. [CrossRef] 
5. Dyson, S.; Berger, J.; Ellis, A.D.; Mullard, J. Development of an ethogram for a pain scoring system in ridden horses and its application to determine the presence of musculoskeletal pain. J. Vet. Behav. 2018, 23, 47-57. [CrossRef]

6. Dyson, S.; Berger, J.; Ellis, A.; Mullard, J. Behavioural observations and comparisons of non-lame horses and lame horses before and after resolution of lameness by diagnostic analgesia. J. Vet. Behav. Clin. Appl. Res. 2018, 26, 64-70. [CrossRef]

7. Dyson, S.; Van Dijk, J. Application of a ridden horse ethogram to video recordings of 21 horses before and after diagnostic analgesia: Reduction in behaviour scores. Equine Vet. Educ. 2018. [CrossRef]

8. Dyson, S.; Thomson, K.; Quiney, L.; Bondi, A.; Ellis, A.D. Can veterinarians reliably apply a whole horse ridden ethogram to differentiate nonlame and lame horses based on live horse assessment of behaviour? Equine Vet. Educ. 2019. [CrossRef]

9. Greve, L.; Dyson, S. Saddle fit and management: An investigation of the association with equine thoracolumbar asymmetries, horse and rider health. Equine Vet. J. 2014, 47, 415-421. [CrossRef]

10. Dyson, S.; Ellis, A.; Quiney, L.; Douglas, J.; Bondi, A.; Harris, P. The Influence of Rider: Horse Bodyweight Ratio on Equine Gait, Behaviour, Response to Thoracolumbar Palpation and Thoracolumbar Dimensions: A Pilot Study. In Proceedings of the 14th International Society of Equitation Science Congress, Rome, Italy, 21-24 September 2018; p. 120.

11. Dyson, S.; Ellis, A.D.; Guire, R.; Douglas, J.; Bondi, A.; Harris, P. The influence of rider: Horse bodyweight ratio and rider-horse-saddle fit on equine gait and behaviour: A pilot study. Equine Vet. Educ. 2019. [CrossRef]

12. Roost, L.; Ellis, A.D.; Morris, C.; Bondi, A.; Gandy, E.A.; Harris, P.; Dyson, S. The effects of rider size and saddle fit for horse and rider on forces and pressure distribution under saddles: A pilot study. Equine Vet. Educ. 2019. [CrossRef]

13. Strunk, R.; Vernon, K.; Blob, R.; Bridges, W.; Skewes, P. Effects of Rider Experience Level on Horse Kinematics and Behavior. J. Equine Vet. Sci. 2018, 68, 68-72. [CrossRef] [PubMed]

14. Dyson, S. Can lameness be reliably graded? Equine Vet. J. 2011, 43, 379-382. [CrossRef] [PubMed]

15. Dyson, S. Evaluation of poor performance in competition horses: A musculoskeletal perspective. Part 1: Clinical assessment. Equine Vet. Educ. 2015, 28, 284-293. [CrossRef]

16. Greve, L.; Dyson, S. What can we learn from visual and objective assessment of non-lame and lame horses in straight lines, on the lunge and ridden? Equine Vet. Educ. 2018. [CrossRef]

17. Boado, A.; Nagy, A.; Dyson, S. Ultrasonographic features associated with the lumbosacral or lumbar 5-6 symphyses in 64 horses with lumbosacral-sacroiliac joint region pain (2012-2018). Equine Vet. Educ. 2019. [CrossRef]

18. Fédération Equestre Internationale. Available online: www.fei.org/fei/regulations/dressage (accessed on 4 March 2020).

19. Benjamini, Y.; Hochberg, Y. Controlling the False Discovery Rate: A Practical and Powerful Approach to Multiple Testing. J. R. Stat. Soc. Ser. B (Methodol.) 1995, 57, 289-300. [CrossRef]

20. Cameron, A.C.; Trivedi, P.K. Microeconometrics Using Stata; Stata Press: College Station, TX, USA, 2009.

21. Terada, K. Comparison of Head Movement and EMG Activity of Muscles between Advanced and Novice Horseback Riders at Different Gaits. J. Equine Sci. 2000, 11, 83-90. [CrossRef]

22. Lagarde, J.; Kelso, J.A.S.; Peham, C.; Licka, T.F. Coordination dynamics of the horse-rider system. J. Mot. Behav. 2005, 37, 418-424. [CrossRef]

23. Münz, A.; Eckardt, F.; Witte, K. Horse-rider interaction in dressage riding. Hum. Mov. Sci. 2014, 33, $227-237$. [CrossRef]

24. Münz, A.; Eckardt, F.; Heipertz-Hengst, C.; Peham, C.; Witte, K. A Preliminary Study of an Inertial Sensor-based Method for the Assessment of Human Pelvis Kinematics in Dressage Riding. J. Equine Vet. Sci. 2013, 33, 950-955. [CrossRef]

25. Schöllhorn, W.I.; Peham, C.; Licka, T.F.; Scheidl, M. A pattern recognition approach for the quantification of horse and rider interactions. Equine Vet. J. 2006, 38, 400-405. [CrossRef] [PubMed]

26. Licka, T.F.; Kapaun, M.; Peham, C. Influence of rider on lameness in trotting horses. Equine Vet. J. 2004, 36, 734-736. [CrossRef] [PubMed]

27. Peham, C.; Licka, T.; Kapaun, M.; Scheidl, M. A new method to quantify harmony of the horse-rider system in dressage. Sports Eng. 2001, 4, 95-101. [CrossRef] 
28. Dyson, S.; Martin, C.; Bondi, A.; Ellis, A.D. Ridden horse exercise: The influence of rider skill on behaviour assessed using the Ridden Horse Ethogram. 2020; Manuscript in preparation.

29. Dyson, S.; Greve, L. Subjective Gait Assessment of 57 Sports Horses in Normal Work: A Comparison of the Response to Flexion Tests, Movement in Hand, on the Lunge, and Ridden. J. Equine Vet. Sci. 2016, 38, 1-7. [CrossRef]

30. Dyson, S.; Murray, R. Pain associated with the sacroiliac joint region: A clinical study of 74 horses. Equine Vet. J. 2003, 35, 240-245. [CrossRef] [PubMed]

31. Dyson, S.; Murray, R. Management of hindlimb proximal suspensory desmopathy by neurectomy of the deep branch of the lateral plantar nerve and plantar fasciotomy: 155 horses (2003-2008). Equine Vet. J. 2012, 44, 361-367. [CrossRef] [PubMed]

32. Barstow, A.; Dyson, S. Clinical features and diagnosis of sacroiliac joint region pain in 296 horses: $2004-2014$. Equine Vet. Educ. 2015, 27, 637-647. [CrossRef]

33. Egenvall, A.; Lönnell, C.; Roepstorff, L. Orthopaedic health status of riding school horses from eight riding schools-A pilot study. Acta Vet. Scan. 2010, 52, 50. [CrossRef]

34. Visser, E.K.; Neijenhuis, F.; De Graaf-Roelfsema, E.; Wesselink, H.G.M.; De Boer, J.; Van Wijhe-Kiezebrink, M.C.; Engel, B.; Van Reenen, C.G. Risk factors associated with health disorders in sport and leisure horses in the Netherlands1. J. Anim. Sci. 2014, 92, 844-855. [CrossRef]

35. Dyson, S. Application of a ridden horse ethogram to horses competing at a 4-star three-day-event: Comparison with cross-country performance. Equine Vet. J. 2019, 51, 11.

36. Dyson, S.; Ellis, A.D. Application of a Ridden Horse Ethogram to horses competing at 5-star three-day-events: Comparison with performance. 2020; Manuscript submitted.

37. Merrifield-Jones, M.; Tabor, G.; Williams, J. Inter- and Intra-Rater Reliability of Soft Tissue Palpation Scoring in the Equine Thoracic Epaxial Region. J. Equine Vet. Sci. 2019, 83, 102812. [CrossRef] [PubMed]

38. Landman, M.A.A.M.; De Blaauw, J.A.; Hofland, L.J.; Van Weeren, P.R. Field study of the prevalence of lameness in horses with back problems. Vet. Rec. 2004, 155, 165-168. [CrossRef] [PubMed]

39. Bondi, A.; Norton, S.; Pearman, L.; Dyson, S. Evaluating the suitability of an English saddle for a horse and rider combination. Equine Vet. Educ. 2019. [CrossRef]

40. Peham, C.; Licka, T.F.; Schobesberger, H.; Meschan, E. Influence of the rider on the variability of the equine gait. Hum. Mov. Sci. 2004, 23, 663-671. [CrossRef] [PubMed]

41. Dyson, S.; Ellis, A.; Mullard, J.; Berger, J. Response to Gleerup: Understanding signals that indicate pain in ridden horses. J. Vet. Behav. 2018, 23, 87-90. [CrossRef]

42. Greve, L.; Dyson, S.; Pfau, T. Alterations in thoracolumbosacral movement when pain causing lameness has been improved by diagnostic analgesia. Vet. J. 2017, 224, 55-63.

43. Persson-Sjodin, E.; Hernlund, E.; Pfau, T.; Andersen, P.H.; Rhodin, M. Influence of seating styles on head and pelvic vertical movement symmetry in horses ridden at trot. PLOS ONE 2018, 13, e0195341. [CrossRef]

44. Hall, C.; Kay, R.; Yarnell, K. Assessing ridden horse behavior: Professional judgment and physiological measures. J. Vet. Behav. 2014, 9, 22-29. [CrossRef]

45. Hall, C.; Huws, N.; White, C.; Taylor, E.; Owen, H.; McGreevy, P. Assessment of ridden horse behavior. J. Vet. Behav. Clin. Appl. Res. 2013, 8, 62-73. [CrossRef]

(C) 2020 by the authors. Licensee MDPI, Basel, Switzerland. This article is an open access article distributed under the terms and conditions of the Creative Commons Attribution (CC BY) license (http://creativecommons.org/licenses/by/4.0/). 